\title{
Médiévales
}

Langues, Textes, Histoire

74 | printemps 2018

Chanter la Croisade albigeoise

Stéphane PÉQUIGNOT et Pierre SAVY (dir.), Annexer ?

Les déplacements de frontières à la fin du Moyen Âge

Rennes, Presses universitaires de Rennes, 2016, 227 p.

\section{Adrien Carbonnet}

\section{(2) OpenEdition}

Journals

Édition électronique

URL : https://journals.openedition.org/medievales/8911

DOI : 10.4000/medievales.8911

ISSN : 1777-5892

Éditeur

Presses universitaires de Vincennes

Édition imprimée

Date de publication : 15 juillet 2018

Pagination : 203-205

ISBN : 978-2-84292-837-7

ISSN : 0751-2708

Référence électronique

Adrien Carbonnet, "Stéphane péauignot et Pierre savy (dir.), Annexer ? Les déplacements de frontières à la fin du Moyen Âge », Médiévales [En ligne], 74 | printemps 2018, mis en ligne le 10 août 2018, consulté le 24 avril 2022. URL : http://journals.openedition.org/medievales/8911 ; DOI : https://doi.org/ 10.4000/medievales.8911

Ce document a été généré automatiquement le 24 avril 2022.

Tous droits réservés 


\section{Stéphane PÉQUIGNOT et Pierre SAVY (dir.), Annexer ? Les déplacements de frontières à la fin du Moyen Âge}

Rennes, Presses universitaires de Rennes, 2016, 227 p.

\section{Adrien Carbonnet}

\section{RÉFÉRENCE}

Stéphane PÉQUIGNOT et Pierre SAVY (dir.), Annexer ? Les déplacements de frontières à la fin du Moyen Âge, Rennes, Presses universitaires de Rennes, 2016, 227 p.

1 Cet ouvrage résulte de deux rencontres qui se sont tenues à l'Université Paris-EstMarne-la-Vallée et à l'École Pratique des Hautes Études en 2012 et 2013 autour de la question de l'annexion et du déplacement des frontières dans l'Occident médiéval. Dans leur riche introduction, les directeurs de l'ouvrage, Stéphane Péquignot et Pierre Savy, reviennent sur les traditions historiographiques et sur les mots de l'annexion pour montrer à quel point le concept est fécond pour l'historien, dans la mesure où il permet de mesurer l'inscription du pouvoir politique dans l'espace et, par-là, la constitution territoriale des États à la fin du Moyen Âge. L'entreprise n'est pas sans risque. Dans l'ombre du lourd héritage historiographique du XIX et du début du XX $x^{\mathrm{e}}$ siècle se cache un danger pour l'historien : être la proie des récits nationaux et envisager l'annexion de façon téléologique. Or, c'est ignorer à quel point cette histoire des déplacements de frontières n'est pas linéaire dans le temps, la frontière est tout sauf fixe. Dès lors, il faut s'attacher à situer les annexions dans la chronologie et à faire émerger les acteurs locaux afin de pouvoir comprendre les enjeux des déplacements (et parfois même des micro-déplacements) de frontières. Neuf contributions et une conclusion de Jean-Marie Moeglin tâchent de donner corps à ce programme selon une démarche comparatiste essentiellement concentrée sur les marges du royaume de France. 
2 La première de ces contributions nous transporte en Catalogne. Flocel Sabaté montre à quel point la cohésion sociale de ce territoire et l'identité partagée par ses habitants furent essentielles dans la constitution de ses frontières au XII ${ }^{\mathrm{e}}$ siècle. Plus que les limites institutionnelles ou socio-économiques, c'est cette conscience identitaire, passant par la représentation politique aux Corts, qui conduit à la délimitation des frontières entre Catalogne et Aragon au sein de la Couronne aux $\mathrm{XIV}^{\mathrm{e}}$ et $\mathrm{Xv}^{\mathrm{e}}$ siècles. Même l'appropriation croissante de la frontière par le souverain, qui incorpore ou soustrait des territoires (c'est le cas du Val d'Aran et de Fenouillèdes, aux frontières du royaume de France), avec le lot de complications que cela représente pour les populations, ne peut mettre fin aux relations économiques, sociales et familiales de part et d'autre de la frontière.

3 La situation est inverse en Corse. À partir de la question "à qui est la Corse ?", Antoine Franzini souligne la difficile territorialisation de cette île qui est une mosaïque de communautés. Sous la souveraineté théorique du Saint-Siège, disputée par la Commune de Gênes et la Couronne d'Aragon, la Corse n'est pas vue comme un territoire à dominer, mais plutôt comme un réservoir à bénéfices pour récompenser des fidèles dont la frontière se limiterait au littoral.

4 Georg Jostkleigrewe s'attache ensuite à la déconstruction du récit de la construction territoriale des États. Partant des historiographies française et allemande sur la question, il s'interroge sur l'existence d'une politique d'expansion territoriale des rois de France sur les terres d'Empire à partir du rattachement de Lyon à la Couronne. La démarche de l'historien a pour but de démonter le discours des sources qui tentent de légitimer ou au contraire de dénoncer les phénomènes d'expansion territoriale. Il encourage la confrontation entre la théorie politique de l'annexion et les pratiques locales, qui permet ici de remettre en cause une politique annexionniste du roi de France.

$5 \quad$ Le discours des sources sur les questions d'expansion territoriale et d'annexion est bien mis en avant par Valérie Theis. Cette dernière, à partir de l'exemple du Comtat Venaissin pontifical, montre à quel point la définition et la délimitation du territoire médiéval peut s'avérer complexe. Durant tout le XIII ${ }^{\mathrm{e}}$ siècle, la Papauté a cherché à consolider ses droits sur le Comtat Venaissin en s'appuyant sur une documentation diverse, pour ensuite, au XIV siècle, en renforcer la cohésion au moyen d'achats et de donations. L'annexion, plus qu'un moment ponctuel, apparait ici comme un véritable processus. Signalons au passage le bel ensemble de cartes qui accompagne cette contribution.

6 La complexité des droits entourant les déplacements de frontières est également éclairée par Anne Lemonde-Santamaria dans son article traitant du transport du Dauphiné à la Couronne de France. Entre le royaume de France et l'Empire, le Dauphiné est un espace où se croisent les influences du roi, du pape, de l'empereur et les acteurs locaux. L'auteur montre ici comment le traité de transport du Dauphiné résulte d'une complexe négociation entre ces acteurs qui ont élaboré un véritable "feuilletage juridique ", qui a créé la frontière plus qu'il ne l'a déplacée, tout en préservant les intérêts de chacun.

7 Élodie Lecuppre-Desjardin, quant à elle, pose la question de la perception territoriale de la "Grande principauté » bourguignonne. Les délimitations de ce vaste ensemble acquis par les ducs Valois à coup de mariages, héritages et conquêtes, sont loin de 
constituer un ensemble flou pour les contemporains. Selon les situations et les acteurs, les modes de représentation de cet ensemble diffèrent, de la simple énumération des possessions aux témoignages de locaux, en passant par la carte qui sert à mettre en avant la souveraineté des ducs sur leur territoire.

Léonard Dauphant retrouve cette même logique territoriale au sein des discours qui définissent le pouvoir royal en France à la fin du Moyen Âge. Toutefois, il ne faudrait pas accorder au roi une véritable politique expansionniste. Comme l'auteur le montre pour les déplacements de frontières touchant la haute Saône et la haute Meuse au Xve siècle, il n'y a pas de volonté de transformer la marche en limite linéaire. Le pouvoir royal ne conçoit pas vraiment l'annexion sur sa frontière orientale, mais a seulement pour volonté de consolider ses marges selon la représentation d'un royaume des « Quatre Rivières ».

9 Cette politique royale de consolidation des marges se retrouve en Italie du Nord où Pierre Savy porte son regard sur le projet de détachement de la Ligurie de l'Empire et de son inclusion dans le royaume de France par Louis XI. Le roi a en effet projeté de retirer Gênes de l'influence impériale pour la remettre en fief au duc de Milan, le faisant de fait souverain de ce territoire et plus seulement son seigneur. Une telle politique, dont Pierre Savy montre toute la complexité, servirait les intérêts du roi et de Francesco Sforza, mais montrerait surtout l'érosion de certaines «frontières immémoriales" à la fin du Moyen Âge, notamment avec l'Empire. La politique territoriale de Louis XI est également au centre de l'article de Stéphane Péquignot portant sur la question de l'annexion du Roussillon au royaume de France pendant la guerre civile catalane. Un véritable processus d'union au royaume est mis au jour. En difficulté, Jean II d'Aragon a en effet fait appel au roi de France en hypothéquant à son profit le Roussillon. Louis XI, profitant de la situation incertaine du roi d'Aragon, put ainsi progressivement contrôler ce territoire par des manipulations juridiques et par la force, tout en maintenant l'ambiguïté de la nature de sa domination. Malgré tout, une fois ce territoire acquis, le roi ne parvint pas à consolider la présence française.

Pour finir, Jean-Marie Moeglin revient dans sa conclusion sur le prétendu flou du Moyen Âge en matière de délimitation de l'espace. Les hommes du Moyen Âge se sont préoccupés des frontières. L'erreur serait de voir cette entreprise uniquement du point de vue du pouvoir souverain, et d'oublier l'importance des acteurs locaux dans ce processus. Une évolution serait toutefois perceptible à la fin $\mathrm{du} \mathrm{Xv}^{\mathrm{e}}$ siècle, où certains princes, le roi de France notamment, n'hésitent plus à déplacer la frontière. Ce dernier est toutefois toujours tenu de légitimer ses conquêtes, ce qui limite la portée de ses annexions.

11 Le point fort de cet ouvrage est donc de souligner à quel point le déplacement des frontières, qui ne peut se limiter au simple concept de l'annexion, n'est pas un processus continu et simple. Le mérite des auteurs de ce livre, à travers l'étude de cas divers et variés, est de montrer à chaque fois l'intrication des droits, des espaces, des acteurs et des intérêts lorsqu'il s'agit de donner une limite à un territoire, qui ne peut jamais se réduire à une ligne. Cette alternance des échelles et cette prise en compte de tous les acteurs pour comprendre le phénomène sont d'une grande richesse méthodologique pour qui veut étudier l'inscription du pouvoir dans l'espace. 


\section{AUTEURS}

\section{ADRIEN CARBONNET}

Sorbonne Université/Centre Roland Mousnier-UMR 8596 